\title{
Intrapulmonary Effects of Setting Parameters in Portable Intrapulmonary Percussive Ventilation Devices
}

\author{
Michel Toussaint PhD, Marie-Charlotte Guillet PT, Stéphanie Paternotte PT, \\ Philippe Soudon MD, and Jurn Haan MD
}

\begin{abstract}
BACKGROUND: Despite potential benefits of intrapulmonary percussive ventilation (IPV) in various respiratory diseases, the impact of setting parameters on the mechanical effects produced by IPV in the lungs is unknown. We hypothesized that changing the parameters on IPV would modulate these effects. This in vitro study aimed at comparing the changes in intrapulmonary effects resulting from changes in parameters in 3 portable IPV devices (IMP2, Impulsator, and Pegaso). METHODS: Parameters were set in 72 combinations of frequency $(90-250 \mathrm{cycles} / \mathrm{min})$, inspiratory to expiratory (I/E) time ratio (from 1/2 to 3/1), and pressure (10-60 $\mathrm{cm} \mathrm{H}_{2} \mathrm{O}$ ). Four resulting effects were recorded on a test lung via a pneumotachometer: the expiratory to inspiratory flow ratio (E/I flow ratio), the PEEP, the ventilation, and the percussion. Percussion was assessed by the end-slope of the pressure curve. Analysis of variance was used for data analysis. RESULTS: $\mathrm{E} / \mathrm{I}$ flow ratio increased with increasing $\mathrm{I} / \mathrm{E}$ time ratio $(P<.001)$. The Pegaso produced the lowest E/I flow ratio. PEEP raised $6 \mathrm{~cm} \mathrm{H}_{2} \mathrm{O}$ in both IMP2 and Impulsator, and $17 \mathrm{~cm} \mathrm{H}_{2} \mathrm{O}$ in the Pegaso with increasing frequency $(P<.01)$, pressure, and $\mathrm{I} / \mathrm{E}$ time ratio $(P<.001)$. In all devices, ventilation increased with increasing pressure and decreasing frequency $(P<.001)$. Percussion increased with increasing frequency and decreasing $I / E$ time ratio $(P<.001)$, and with increasing pressure when I/E time ratio was $1 / 1$ or less. The Pegaso provided the poorest percussion. CONCLUSIONS: This study suggests that changing the parameters considerably modulates the mechanical effects produced by portable IPV devices in the lungs. Increasing frequency increased PEEP and percussion, but decreased ventilation. Increasing I/E time increased PEEP and E/I flow ratio, and decreased percussion. Finally, increasing pressure increased PEEP and ventilation. The Pegaso produced the highest PEEP, least percussion, and smallest change in E/I flow ratio. Key words: airway clearance; chest physiotherapy; intrapulmonary percussive ventilation; mисus clearance. [Respir Care 2012;57(5):735-742. (C) 2012 Daedalus Enterprises]
\end{abstract}

\section{Introduction}

Intrapulmonary percussive ventilation (IPV) is a pneumatic device for providing chest physiotherapy. IPV is expected to loosen and mobilize secretions toward the upper airways in patients with restrictive and obstructive

\footnotetext{
The authors are affiliated with the Acute Neurorespiratory Rehabilitation Unit, Neuromuscular Excellency Centre, Vrije Universiteit Brussel-Inkendaal and Centre for Home Mechanical Ventilation, Ziekenhuis Inkendaal Rehabilitation Hospital, Brussels, Belgium.

Supplementary material related to this paper is available at http:// www.rcjournal.com.
}

The authors have disclosed no conflicts of interest. pulmonary diseases affected by severe endobronchial encumbrance. IPV delivers high-frequency ventilation into the lungs, in the form of intrapulmonary percussions. Percussions, ranging from 60 to 400 cycles/min, consist of small bursts of volume characterized by sharp peaks of pressure (Fig. 1). IPV may be delivered via a face mask, a mouthpiece, an endotracheal tube, or a tracheostomy. Recent reports have suggested that IPV facilitates airway

\footnotetext{
Correspondence: Michel Toussaint PhD, Ziekenhuis Inkendaal Rehabilitation Hospital, Inkendaalstraat 1, 1602 Vlezenbeek, Belgium, Brussels. E-mail: michel.toussaint@inkendaal.be.
}

DOI: $10.4187 /$ respcare. 01441 

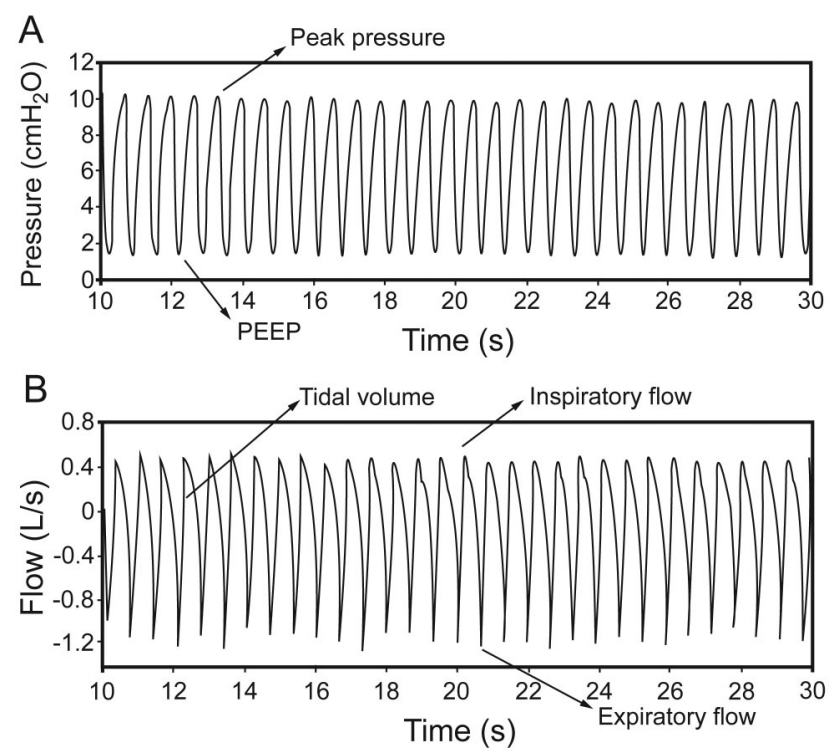

Fig. 1. Typical curve of pressure (A) and flow (B) with intrapulmonary percussive ventilation (IPV) devices (in casu IMP2 with frequency of $180 \mathrm{cycles} / \mathrm{min}$, I/E time ratio of 2/1, and pressure of $10 \mathrm{~cm} \mathrm{H}_{2} \mathrm{O}$ ). The area under the flow-time curve for each breath represents the tidal volume.

clearance and improves homogeneity of ventilation in patients with cystic fibrosis, ${ }^{1-5}$ in patients with neuromuscular disorders with retention of mucus, ${ }^{6,7}$ in patients with atelectasis, ${ }^{8-10}$ in burned patients with inhalation injury, ${ }^{11-13}$ and in patients with COPD. ${ }^{14-17}$

Despite potential benefits related to the use of IPV therapy, the impact of setting parameters such as the ratio of inspiratory to expiratory time, the pressure, and the frequency on the mechanical effects produced by IPV devices is totally unknown. As a consequence, no evidence is available to advise caregivers on how to set parameters to conduct their therapies. We hypothesized that changing the settings on IPV would modulate these mechanical effects in the lungs. In this in vitro investigation, we aimed at measuring and quantifying changes in mechanical effects resulting from changes in parameter settings in portable IPV devices.

\section{Methods}

Three IPV devices equipped with their own internal compressors, the IMP2 (Breas, Mölnlycke, Sweden), the Impulsator (Percussionaire, Sandpoint, Idaho), and the Pegaso (Dima, Bologna, Italia), were compared. In order to standardize the setting of parameters in all devices, parameters were set following monitoring via a heated Fleisch no. 2 pneumotachometer (Metabo, Lausanne, Switzerland) placed in line between the IPV circuit and an adult test lung (SmartLung, IMT Medical, Buchs, Switzerland). The

\section{QUICK LOOK}

\section{Current knowledge}

Intrapulmonary percussive ventilation (IPV) devices provide a method for secretion removal that includes both hyperinflation and internal percussion.

\section{What this paper contributes to our knowledge}

Changing the settings of IPV devices alters the mechanical effects in the lungs. Increasing the frequency results in an increase in PEEP and percussion, but decreased ventilation. Increasing the inspiratoryexpiratory time ratio increases PEEP and expiratoryinspiratory flow ratio, and decreases percussion. Increasing the pressure increases PEEP and ventilation. Manipulation of IPV settings to maximize ventilation, secretion removal, and lung inflation is possible.

characteristics of the lung were set at the highest compliance $\left(30 \mathrm{~mL} / \mathrm{cm} \mathrm{H}_{2} \mathrm{O}\right)$ and lowest resistance $\left(5 \mathrm{~cm} \mathrm{H}_{2} \mathrm{O} /\right.$ $\mathrm{L} / \mathrm{s}$ ) of the test lung. Volumes and timing of ventilation were obtained by integration of flow signals. Recorded data were computed in a data analyzer (MEC, Medical Electronic Construction, Brussels, Belgium).

\section{Parameters on IPV}

Parameters on IPV were successively combined in 3 conditions of frequency (90,180, and 250 cycles/min); 4 conditions of inspiratory to expiratory (I/E) time ratio (1/2, $1 / 1,2 / 1$, and $3 / 1$ ); and 6 conditions of pressure (10$60 \mathrm{~cm} \mathrm{H}_{2} \mathrm{O}$ ). At our request, the $50 \mathrm{~cm} \mathrm{H}_{2} \mathrm{O}$ high pressure limit on the IMP2 was suppressed by the manufacturer to allow comparable pressures in all devices. This study allowed the comparison of 72 combinations recorded each during 30 seconds. The first 10 seconds were necessary to allow stability of the compressors and were therefore not considered for analysis.

\section{Mechanical Effects In the Lung}

As previously described, ${ }^{18} 4$ mechanical effects were compared: the ratio of expiratory to inspiratory flow (E/I flow ratio), the ventilation as assessed by the tidal volume $\left(\mathrm{V}_{\mathrm{T}}\right)$, the PEEP, and the percussion. The sharpness of percussion was assessed by the slope of the pressure curve, measured $60 \mathrm{~ms}$ prior to the peak of pressure. Higher slope values indicated steeper inclines, which in turn estimated sharper peaks of pressure curve. Data were analyzed during the first 20 cycles recorded between the 10th and the 30 th second of recording. Figure 1 represents typical pres- 
sure (see Fig. 1A) and flow (see Fig. 1B) curve measurements.

\section{Analysis}

Analysis of variance (ANOVA) was used to assess the variation of the parameters in the 72 setting combinations in each device (1-way ANOVA) and to compare the 3 devices in the same combination (2-way ANOVA). Software (Medcalc, Mariakerke, Belgium) was used for statistical analysis. Significance was accepted at $P<.05$.

\section{Results}

\section{Expiratory-Inspiratory Flow Ratio}

Due to the characteristics of its internal air compressor, the Impulsator provided a smaller range of I/E time ratio settings, as compared to other IPV devices, at frequencies set at 180 and 250 cycles/min. Figures 2 and 3 depict E/I flow ratios with frequencies at 90 and 250 cycles/min, respectively. In general, the $\mathrm{E} / \mathrm{I}$ flow ratio increased with increasing $\mathrm{I} / \mathrm{E}$ time ratio in the 3 devices $(P<.001)$, but an exception was found with pressures $\geq 30 \mathrm{~cm} \mathrm{H}_{2} \mathrm{O}$ and frequency at 90 cycles/min with the Pegaso. The highest E/I flow ratios were found with the IMP2. The lowest E/I flow ratios were found with the Pegaso. With frequencies at $90 \mathrm{cycles} / \mathrm{min}$ (with pressures $\leq 30 \mathrm{~cm} \mathrm{H}_{2} \mathrm{O}$ ), $180 \mathrm{cy}$ cles/min, and 250 cycles/min the Impulsator provided lower E/I flow ratios than the IPM2.

With the exception of I/E time ratio at 3/1 with a frequency at 90 cycles/min in the Impulsator (see Fig. 2B), increasing pressure did not change the E/I flow ratios. In the IMP2 solely, E/I flow ratios were higher at low $\left(<20 \mathrm{~cm} \mathrm{H}_{2} \mathrm{O}\right)$ and high $\left(>40 \mathrm{~cm} \mathrm{H}_{2} \mathrm{O}\right)$ pressures for a timing ratio of $1 / 1$ in the 3 conditions of frequencies. As a general rule, changes in frequency did not affect E/I flow ratios.

\section{PEEP}

A PEEP was always present in the 3 IPV devices. However, IMP2 and Impulsator could not achieve the set pressure for some of the longer I/E ratios. Table 1 reports available PEEP values. The highest PEEP was found at the highest frequency, set at 250 cycles/min. PEEP increased with increasing pressure $(P<.001)$ and frequency $(P=$ .008 ) from 0.5 to $6 \mathrm{~cm} \mathrm{H}_{2} \mathrm{O}$ in both IMP2 and Impulsator, and from 2.4 to $17 \mathrm{~cm} \mathrm{H}_{2} \mathrm{O}$ with the Pegaso. Increasing I/E time ratio increased PEEP in the 3 conditions of frequency $(P<.001)$. The influence of $\mathrm{I} / \mathrm{E}$ time ratio on PEEP was larger with the Pegaso than with the other IPV devices.
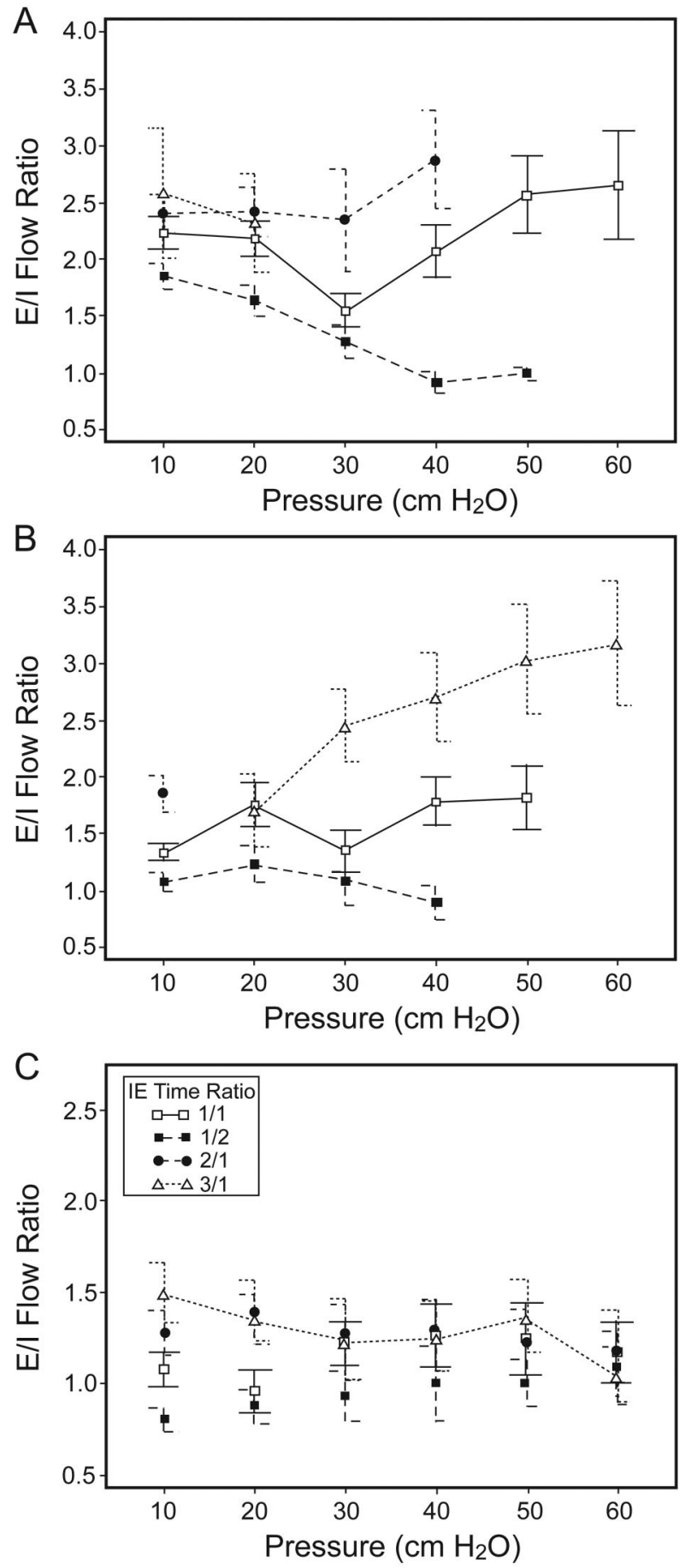

Fig. 2. Changes in expiratory-inspiratory (E/I) flow ratio with increasing pressure at frequency of 90 cycles/min. A: IMP2. B: Impulsator. C: Pegaso.

\section{Ventilation}

As a general trend, increasing pressure significantly increased $\mathrm{V}_{\mathrm{T}}$ in all combinations of frequencies and $\mathrm{I} / \mathrm{E}$ time ratios $(P<.001)$. The largest $\mathrm{V}_{\mathrm{T}}$, presented in Table 2 , 

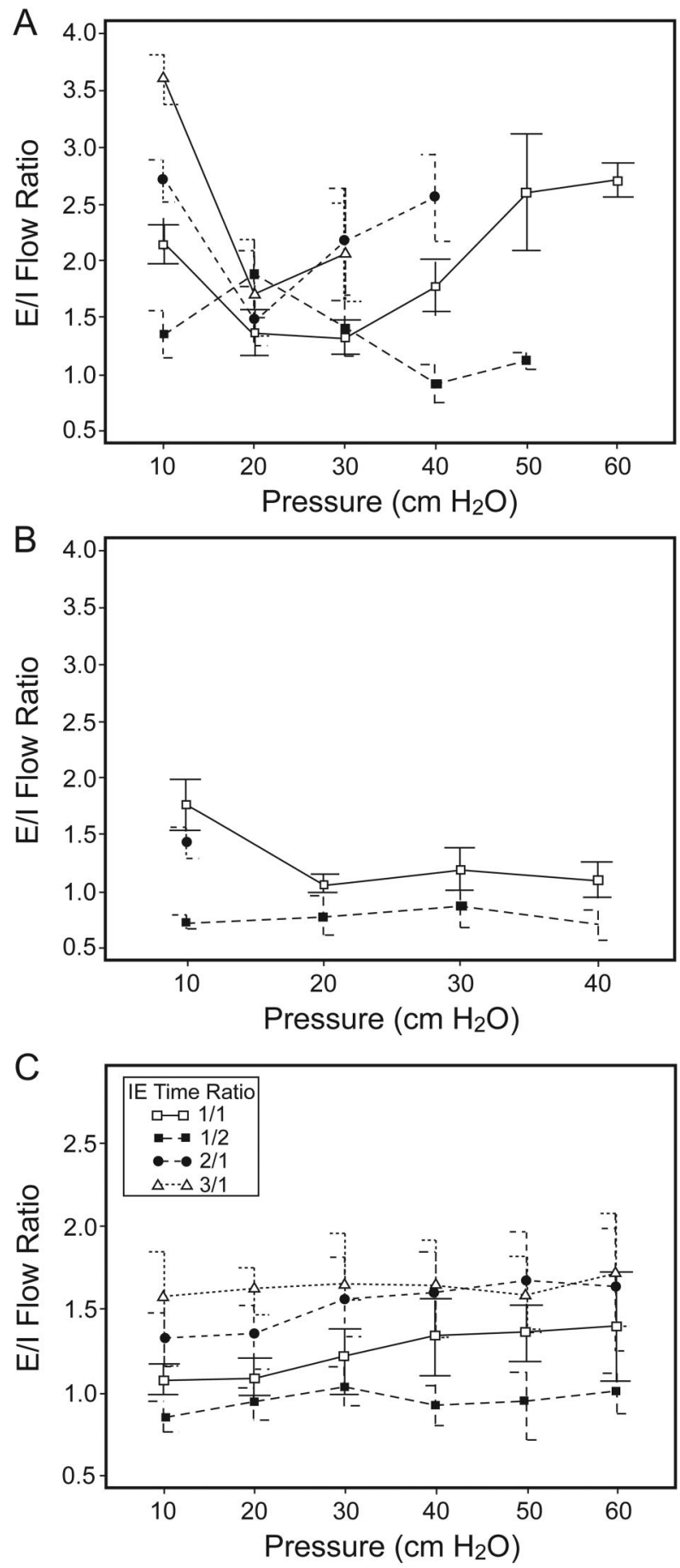

Fig. 3. Changes in expiratory-inspiratory (E/I) flow ratio with increasing pressure at frequency of $250 \mathrm{cycles} / \mathrm{min}$. A: IMP2. B: Impulsator. C: Pegaso.

were found with the lowest frequencies in all devices $(P<.001)$. At similar frequencies, inconsistent differences in $\mathrm{V}_{\mathrm{T}}$ were found among the devices. However, at a frequency of 90 cycles $/ \mathrm{min}, \mathrm{V}_{\mathrm{T}}$ was larger with the IMP2 and Impulsator than with the Pegaso with $\mathrm{I} / \mathrm{E}$ time ratios
Table 1. PEEP With a Constant Frequency at 250 Cycles/Min and Increasing I/E Time Ratio and Pressure

\begin{tabular}{ccccc}
\hline \hline \multirow{2}{*}{$\begin{array}{c}\text { I/E } \\
\text { Time } \\
\text { Ratio }\end{array}$} & $\begin{array}{c}\text { Pressure, } \\
\mathrm{cm} \mathrm{H}_{2} \mathrm{O}\end{array}$ & \multicolumn{3}{c}{ PEEP, mean $\pm \mathrm{SD} \mathrm{cm} \mathrm{H}_{2} \mathrm{O}$} \\
\cline { 3 - 5 } $1 / 2$ & 10 & $0.67 \pm 0.02^{*}$ & $0.43 \pm 0.01^{*}$ & $2.37 \pm 0.10^{*}$ \\
& 20 & $0.98 \pm 0.01$ & $0.53 \pm 0.02$ & $4.88 \pm 0.05$ \\
& 30 & $1.57 \pm 0.05$ & $1.59 \pm 0.04$ & $5.73 \pm 0.28$ \\
& 40 & $2.20 \pm 0.04$ & $1.95 \pm 0.03$ & $8.42 \pm 0.14$ \\
& 50 & $3.53 \pm 0.07$ & NA & $9.40 \pm 0.23$ \\
& 60 & NA & NA & $10.58 \pm 0.31$ \\
$1 / 1$ & 10 & $1.51 \pm 0.03^{*}$ & $0.89 \pm 0.08^{*}$ & $3.21 \pm 0.32 *$ \\
& 20 & $2.51 \pm 0.06$ & $0.62 \pm 0.09$ & $6.71 \pm 0.10$ \\
& 30 & $4.61 \pm 0.07$ & $3.46 \pm 0.05$ & $7.82 \pm 0.13$ \\
& 40 & $4.41 \pm 0.08$ & $3.82 \pm 0.09$ & $9.30 \pm 0.22$ \\
& 50 & $4.62 \pm 0.08$ & NA & $11.01 \pm 0.26$ \\
& 60 & $4.97 \pm 0.08$ & NA & $12.69 \pm 0.40$ \\
$2 / 1$ & 10 & $2.21 \pm 0.04 *$ & $1.30 \pm 0.05$ & $2.45 \pm 0.10^{*}$ \\
& 20 & $4.75 \pm 0.06$ & NA & $5.03 \pm 0.18$ \\
& 30 & $5.18 \pm 0.06$ & NA & $6.47 \pm 0.39$ \\
& 40 & $5.99 \pm 0.12$ & NA & $8.53 \pm 0.68$ \\
& 50 & NA & NA & $10.72 \pm 0.59$ \\
& 60 & NA & NA & $14.04 \pm 0.37$ \\
$3 / 1$ & 10 & $2.26 \pm 0.09 *$ & NA & $4.13 \pm 0.19 *$ \\
& 20 & $2.92 \pm 0.15$ & NA & $6.44 \pm 0.27$ \\
& 30 & $5.22 \pm 0.09$ & NA & $8.51 \pm 0.47$ \\
& 40 & NA & NA & $10.70 \pm 0.65$ \\
& 50 & NA & NA & $13.58 \pm 0.90$ \\
& 60 & NA & NA & $17.01 \pm 1.13$
\end{tabular}

* One-way analysis of variance (ANOVA) for PEEP versus pressure within the same inspiratory to expiratory (I/E) time ratio, $P<.001$. Two-way ANOVA for PEEP differences among devices: at I/E $1 / 2$, Pegaso $>$ Impulsator and IMP2 $(P<.001)$; at I/E $1 / 1$, Pegaso $>$ IMP2 $>$ Impulsator; at I/E $2 / 1$, Pegaso $>$ IMP2 $(P<.001)$; at I/E 3/1, Pegaso $>$ IMP2 $(P<.001)$.

$\mathrm{NA}=$ not available

from $1 / 2$ to $2 / 1$ and with pressures superior to $30 \mathrm{~cm} \mathrm{H}_{2} \mathrm{O}$. With a frequency of 180 cycles/min, $\mathrm{V}_{\mathrm{T}}$ ranged $110-210$, $100-220$, and $100-240 \mathrm{~mL}$ with the IMP2, Impulsator, and Pegaso, respectively. With a frequency of 250 cycles/ min, $\mathrm{V}_{\mathrm{T}}$ was lower than $160 \mathrm{~mL}$ in the 3 devices. Finally, changes in $\mathrm{I} / \mathrm{E}$ time ratio did not affect $\mathrm{V}_{\mathrm{T}}$.

\section{Percussion}

Typical pressure curves are shown at high (Fig. 4A) and low frequency (see Fig. 4B). In all devices, the slope of pressure increased with increasing frequency and decreasing $\mathrm{I} / \mathrm{E}$ time ratio $(P<.001)$. The higher slope values, presented in Table 3, were recorded at a frequency of 250 cycles/min. With decreasing E/I time ratio in the IMP2, Impulsator, and Pegaso, respectively, slopes ranged 7-180, 9-111, and 3-125 $\mathrm{cm} \mathrm{H}_{2} \mathrm{O} / \mathrm{s}$ with a frequency of $90 \mathrm{cy}-$ cles/min, while slopes ranged 19-175, 15-119, and $7-133 \mathrm{~cm} \mathrm{H}_{2} \mathrm{O} / \mathrm{s}$ with a frequency of 180 cycles/min. By 
Table 2. Tidal Volume With a Constant Frequency at 90 Cycles/ Min and Increasing I/E Time Ratio and Pressure

\begin{tabular}{|c|c|c|c|c|}
\hline \multirow{2}{*}{$\begin{array}{c}\text { I/E } \\
\text { Time } \\
\text { Ratio }\end{array}$} & \multirow{2}{*}{$\begin{array}{l}\text { Pressure, } \\
\mathrm{cm} \mathrm{H}_{2} \mathrm{O}\end{array}$} & \multicolumn{3}{|c|}{ Tidal Volume, mean \pm SD L } \\
\hline & & IMP2 & Impulsator & Pegaso \\
\hline \multirow[t]{6}{*}{$1 / 2$} & 10 & $0.14 \pm 0.01 *$ & $0.14 \pm 0.01 *$ & $0.14 \pm 0.01 *$ \\
\hline & 20 & $0.21 \pm 0.01$ & $0.19 \pm 0.01$ & $0.21 \pm 0.02$ \\
\hline & 30 & $0.27 \pm 0.03$ & $0.29 \pm 0.03$ & $0.27 \pm 0.03$ \\
\hline & 40 & $0.34 \pm 0.04$ & $0.36 \pm 0.04$ & $0.34 \pm 0.06$ \\
\hline & 50 & $0.42 \pm 0.04$ & NA & $0.35 \pm 0.05$ \\
\hline & 60 & NA & NA & $0.32 \pm 0.04$ \\
\hline \multirow[t]{6}{*}{$1 / 1$} & 10 & $0.13 \pm 0.01 *$ & $0.13 \pm 0.01 *$ & $0.15 \pm 0.01 *$ \\
\hline & 20 & $0.24 \pm 0.02$ & $0.26 \pm 0.01$ & $0.25 \pm 0.02$ \\
\hline & 30 & $0.37 \pm 0.03$ & $0.35 \pm 0.03$ & $0.29 \pm 0.03$ \\
\hline & 40 & $0.40 \pm 0.05$ & $0.37 \pm 0.04$ & $0.27 \pm 0.04$ \\
\hline & 50 & $0.38 \pm 0.04$ & $0.40 \pm 0.04$ & $0.26 \pm 0.03$ \\
\hline & 60 & $0.41 \pm 0.05$ & NA & $0.31 \pm 0.04$ \\
\hline \multirow[t]{6}{*}{$2 / 1$} & 10 & $0.12 \pm 0.01^{*}$ & $0.14 \pm 0.01$ & $0.19 \pm 0.01^{*}$ \\
\hline & 20 & $0.23 \pm 0.01$ & NA & $0.20 \pm 0.02$ \\
\hline & 30 & $0.26 \pm 0.03$ & NA & $0.21 \pm 0.02$ \\
\hline & 40 & $0.25 \pm 0.04$ & NA & $0.19 \pm 0.02$ \\
\hline & 50 & NA & NA & $0.21 \pm 0.03$ \\
\hline & 60 & NA & NA & $0.24 \pm 0.03$ \\
\hline \multirow[t]{6}{*}{$3 / 1$} & 10 & $0.11 \pm 0.01$ & NA & $0.17 \pm 0.02$ \\
\hline & 20 & $0.12 \pm 0.01$ & $0.11 \pm 0.01$ & $0.20 \pm 0.02$ \\
\hline & 30 & NA & $0.14 \pm 0.01$ & $0.17 \pm 0.02$ \\
\hline & 40 & NA & $0.16 \pm 0.01$ & $0.20 \pm 0.02$ \\
\hline & 50 & NA & NA & $0.23 \pm 0.03$ \\
\hline & 60 & NA & NA & $0.22 \pm 0.03$ \\
\hline
\end{tabular}

* One-way analysis of variance for tidal volume versus pressure within the same inspiratory to expiratory (I/E) time ratio, $P<.001$. Differences among devices were not noteworthy.

$\mathrm{NA}=$ not available

contrast with large I/E time ratios ( $\geq 2 / 1)$, the sharpness of the peaks of pressure increased with increasing pressure when $\mathrm{I} / \mathrm{E}$ time ratios were small $(\leq 1 / 1)$. Extensive slope data for the IMP2, Impulsator, and Pegaso are reported in the tables in the supplementary materials at http://www. rcjournal.com. As shown in Figure 4, the IMP2 was similar to the Impulsator in producing sharp slopes, while the Pegaso provided lesser degrees of slope sharpness. The impact of setting parameters on the mechanical effects produced by portable IPV devices is summarized in Table 4.

\section{Discussion}

This study aimed at determining the impact of setting parameters on 4 mechanical effects produced by IPV in a test lung. To our knowledge, this is the first study mapping mechanical effects of IPV devices.

\section{Expiratory-Inspiratory Flow Ratio}

The first finding of this study was that E/I flow ratio consistently increased with increasing I/E time ratio, in all circumstances and devices. This finding had previously never been demonstrated with IPV devices and should explain in part how IPV therapy potentially supports mucus clearance. The clinical interest of increasing expiratory flows is intuitively evident: effective mucus clearance is expected when the expiratory flows exceed the inspiratory flows by a certain amount. ${ }^{18}$

Previous in vitro and in vivo studies already demonstrated that increased expiratory flows induced by increased inspiratory time favor mucus clearance. Kim et al ${ }^{19}$ investigated in vitro flow models with mechanical ventilation, maintaining E/I flow ratios at $1.5 / 1,2 / 1$, and $3 / 1$. They found that mucus transport speed linearly increased with increasing E/I flow ratio. In an in vivo study, Benjamin et $\mathrm{al}^{20}$ instilled mucus into the bronchi of mechanically ventilated anesthetized sheep. In this study, they compared inverse $\mathrm{I} / \mathrm{E}$ time ratios (inspiratory greater than expiratory time) at $1.9 / 1$ and $3 / 1$ versus a conventional $\mathrm{I} / \mathrm{E}$ time ratio set at $1 / 2.7$. I/E time modes of $1.9 / 1$ and $3 / 1$ produced $E / I$ flow ratios of 2.2/1 and 3/1, promoting transport of mucus, while the I/E time ratio of $1 / 2.7$ did not clear mucus, with an unfavourable E/I flow ratio recorded at 1/1.6. The authors concluded that inverse time ratio ventilation might be useful in the management of excessive bronchial secretions in mechanically ventilated patients.

These findings are consistent with those of King et al. ${ }^{21}$ Again, expiratory flow bias (expiratory $>$ inspiratory flow) was compared with inspiratory flow bias in anesthetized dogs receiving mechanical ventilation with high frequency oscillations at $13 \mathrm{~Hz}$. They found that mucus clearance was 2.4 times higher with expiratory bias than with inspiratory bias. In another in vivo study on anesthetized sheep, Freitag et $a^{22}$ evaluated whether high frequency oscillations with biased expiratory flow profile was capable of augmenting mucus clearance. They compared expiratory bias (E/I flow ratio of 2.9/1) with inspiratory bias oscillations (E/I flow ratio of $1 / 2.9$ ). As in the previous studies, significant clearance was measured when expiratory flows were greater than inspiratory flows.

Interestingly, Volpe et al $^{23}$ recently investigated the conditions of flow necessary to support the movement of airway secretions. In an in vitro study using photodensitometry to measure the center-of-mass displacement of mucus, they found that the minimal value of E/I flow ratio to move mucus toward the mouth was $1.3 / 1$. Under the threshold value of 1.3/1, mucus was transported toward the peripheral airways. By contrast with the Pegaso, which did not reach the threshold value suggested by Volpe's group, the IMP2 and Impulsator were both able to provide an asymmetric flow ratio greater than $1.3 / 1$, therefore potentially enabling mucus transport in the direction of the expiratory flow. In the present study, the best way to increase $\mathrm{E} / \mathrm{I}$ flow ratios was found to be increasing the I/E time ratio. Unfortunately, IMP2 and Impulsator are not designed 


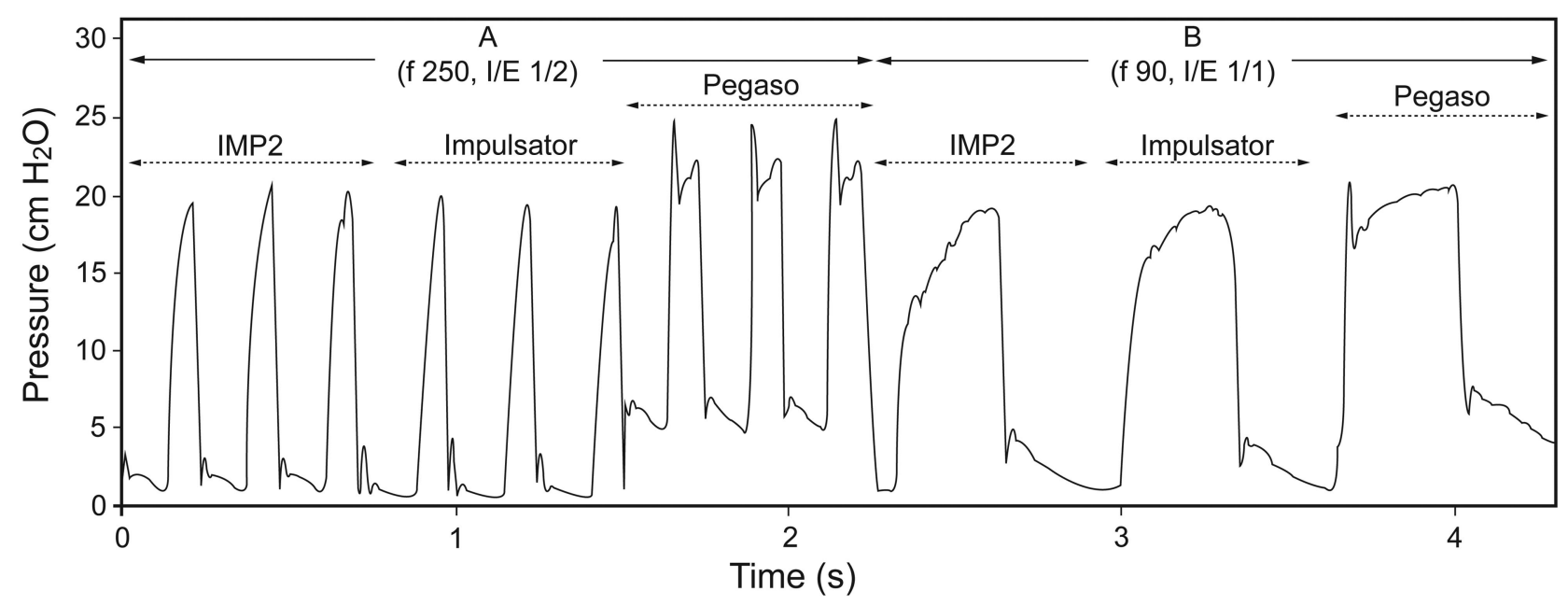

Fig. 4. Typical pressure curves of the 3 intrapulmonary percussive ventilation devices at high and low frequency. A: Frequency of 250 cycles/min, inspiratory-expiratory (I/E) time ratio of 1/2. B: Frequency of 90 cycles/min, I/E time ratio of $1 / 1$. Note that high frequency (A) shows sharper slopes of pressures than does low frequency (B) in the 3 devices.

Table 3. Slopes of the Pressure Curve With a Frequency at 250 Cycles/Min and Increasing I/E Time Ratio and Pressure

\begin{tabular}{|c|c|c|c|c|}
\hline \multirow{2}{*}{$\begin{array}{l}\text { I/E } \\
\text { Time } \\
\text { Ratio }\end{array}$} & \multirow{2}{*}{$\begin{array}{l}\text { Pressure, } \\
\mathrm{cm} \mathrm{H}_{2} \mathrm{O}\end{array}$} & \multicolumn{3}{|c|}{$\begin{array}{c}\text { Slope of Pressure Curve, mean } \pm \mathrm{SD} \mathrm{cm} \mathrm{H} \mathrm{H}_{2} \mathrm{O} / \mathrm{s} \\
\text { at } 250 \text { cycles/min }\end{array}$} \\
\hline & & IMP2 & Impulsator & Pegaso \\
\hline \multirow[t]{6}{*}{$1 / 2$} & 10 & $99.9 \pm 8.7^{*}$ & $85.3 \pm 5.6^{*}$ & $24.3 \pm 6.8 *$ \\
\hline & 20 & $136.8 \pm 32.6$ & $235.1 \pm 56.8$ & $41.2 \pm 2.5$ \\
\hline & 30 & $211.2 \pm 78$ & $305.4 \pm 115.1$ & $32.1 \pm 12.1$ \\
\hline & 40 & $214.9 \pm 21.9$ & $394.9 \pm 104.3$ & $90.9 \pm 0.9$ \\
\hline & 50 & $274 \pm 53.1$ & NA & $127.8 \pm 9.7$ \\
\hline & 60 & NA & NA & $167.5 \pm 3.5$ \\
\hline \multirow[t]{6}{*}{$1 / 1$} & 10 & $26 \pm 4.3^{*}$ & $50.3 \pm 12$ & $21.9 \pm 2.7^{*}$ \\
\hline & 20 & $51.6 \pm 6$ & $69.9 \pm 9.1$ & $35.7 \pm 2.4$ \\
\hline & 30 & $35 \pm 2.7$ & $14.5 \pm 0.8$ & $63.4 \pm 3.3$ \\
\hline & 40 & $122.3 \pm 5.3$ & $76 \pm 8.6$ & $88.8 \pm 2.4$ \\
\hline & 50 & $172.3 \pm 2.9$ & NA & $117.5 \pm 5.9$ \\
\hline & 60 & $214.9 \pm 5.3$ & NA & $132.7 \pm 4.8$ \\
\hline \multirow[t]{6}{*}{$2 / 1$} & 10 & $25.8 \pm 3^{*}$ & $43.5 \pm 15.5$ & $6.9 \pm 1.8^{*}$ \\
\hline & 20 & $22 \pm 2.3$ & NA & $10.8 \pm 0.3$ \\
\hline & 30 & $66.2 \pm 4.2$ & NA & $28.1 \pm 2.2$ \\
\hline & 40 & $101.8 \pm 5.4$ & NA & $40.2 \pm 2.2$ \\
\hline & 50 & NA & NA & $46.2 \pm 10.3$ \\
\hline & 60 & NA & NA & $46.1 \pm 3$ \\
\hline \multirow[t]{6}{*}{$3 / 1$} & 10 & NA & $20.9 \pm 2.3^{*}$ & $6.9 \pm 0.5$ \\
\hline & 20 & NA & $23.7 \pm 1.2$ & $20.4 \pm 1.9$ \\
\hline & 30 & NA & $62 \pm 1.6$ & $60.9 \pm 3.6$ \\
\hline & 40 & NA & NA & $11.5 \pm 7.5$ \\
\hline & 50 & NA & NA & $25.2 \pm 6.8$ \\
\hline & 60 & NA & NA & $40.6 \pm 5.8$ \\
\hline
\end{tabular}

* One-way analysis of variance (ANOVA) for slope versus pressure within the same inspiratory to expiratory $(\mathrm{I} / \mathrm{E})$ time ratio, $P<.001$. Two-way ANOVA for slope differences among devices: at I/E $1 / 2$, Impulsator $>\mathrm{IMP} 2>$ Pegaso $(P<.001)$; at $\mathrm{I} / \mathrm{E} 1 / 1$, no differences between the 3 devices; at I/E 2/1, IMP2 $>$ Pegaso $(P<.001)$; at I/E 3/1, no comparison available.

$\mathrm{NA}=$ not available
Table 4. Impact of Setting Parameters on the Mechanical Effects Produced by Intrapulmonary Percussive Ventilation in the Lungs

\begin{tabular}{ll}
\hline \hline Setting Parameter & \multicolumn{1}{c}{ Mechanical Effects } \\
\hline Frequency $\uparrow$ & Percussion $\uparrow$ \\
& Tidal volume $\downarrow$ \\
& PEEP $\uparrow$ \\
& No effect on expiratory flow \\
& Percussion $\downarrow$ \\
I/E time $\uparrow$ & No effect on tidal volume \\
& PEEP $\uparrow$ \\
& Expiratory flow $\uparrow$ \\
& Percussion $\uparrow$ with little I/E time \\
& Tidal volume $\uparrow$ \\
Pressure $\uparrow$ & PEEP $\uparrow$ \\
& No effect on expiratory flow An exception \\
& when I/E time at 3/1 and frequency at \\
& 90 cycles/min \\
\hline I/E time = inspiratory to expiratory time ratio \\
\hline
\end{tabular}

to work with long inspiratory times (ie, I/E time ratio of $2 / 1$ or $3 / 1$ ). We would advise the manufacturers to enlarge this technical possibility in the future. Interestingly, adequate $\mathrm{E} / \mathrm{I}$ flow ratios were found at all pressures, including those pressures under $20 \mathrm{~cm} \mathrm{H}_{2} \mathrm{O}$. This is useful since low pressures are commonly used in clinical practice. In the cases where the therapeutic goal is to optimize the transport of mucus, caregivers using IPV devices should be advised to use low pressures and to prolong the inspiratory time, aiming at enlarging expiratory flows.

In addition to the possible role of asymmetric flow ratios in clearing excessive bronchial secretions, the present data should also explain in part why the deposition of 
medication via the nebulizer of the IPV was found to be poor with IPV devices. ${ }^{24}$ Adequate deposition would require quiet inspiration with slow expiration, rather than a breathing pattern of higher expiratory than inspiratory flows, such as presently found with IPV.

\section{PEEP}

PEEP was previously found in every technique of highfrequency assisted airway clearance. ${ }^{18}$ Present in all combinations of parameters in our study, PEEP increased with pressure and I/E time ratio. To our surprise, a huge and uncontrollable PEEP was found with the Pegaso, while it remained low with all other IPV devices.

In patients with obstructive disease, PEEP effect has been suggested as useful in stabilizing the bronchial tree, removing secretions, ${ }^{25}$ improving ventilation, and reducing trapped air. ${ }^{26}$ When produced by IPV, PEEP has been shown to reduce expiratory flow limitation and work of breathing in COPD patients. ${ }^{14,17}$ In subjects without flow limitation, IPV may increase the work of breathing. PEEP may cause substantial discomfort, worsen gas exchange, and decrease cardiac output. The use of Pegaso should therefore be avoided in weak patients at risk for developing hypercapnia or cardiac insufficiency.

\section{Ventilation}

An important expected finding, however, was that increasing pressure and decreasing frequencies increased ventilation, as assessed by increasing $\mathrm{V}_{\mathrm{T}}$, while increasing I/E time ratio did not. This is consistent with Nava et al, ${ }^{14}$ who showed that low frequencies ventilated and unloaded respiratory muscles better than high frequencies. Patients with little or no breathing autonomy therefore should require low frequencies, which are able to ventilate the lungs with comfort. ${ }^{6}$ Similarly, low frequencies, high pressures, and long inspiratory times should be selected by caregivers when the therapeutic goal is to provide hyperinsufflations. ${ }^{27,28}$

\section{Percussion}

The last finding was that percussions increased with increasing frequency and decreasing $\mathrm{I} / \mathrm{E}$ time ratio. This was found in all IPV devices. Percussions also increased with increasing pressure when $\mathrm{I} / \mathrm{E}$ time ratio was $1 / 1$ or less. Percussive ventilation has consistently been reported as an effective method to improve blood gas exchange. ${ }^{8,15,17,29,30}$ Caregivers should therefore increase frequency and pressure, and decrease I/E time ratio when they wish to promote percussion in IPV devices.

\section{Differences Among Tested IPV Devices}

The Pegaso provided the largest range of settings. In general, the IMP2 and Impulsator provided similar effects. The IMP2 was the best device in producing elevated E/I flow ratios, while the lowest E/I flow ratios were found with the Pegaso. The latter produced abnormally elevated PEEP, while the 2 other devices produced low ones. The Pegaso also provided lesser degrees of percussion than the other 2 devices.

\section{Rationale for Choosing Appropriate Settings}

According to the targeted therapeutic goals, this study suggests new ways of setting the output of portable IPV devices (see Table 4). When airway clearance is the primary goal of therapy, caregivers should be advised to prolong the inspiratory time, therefore increasing expiratory flows, potentially improving mucus transport. In this case, the choice of the frequency and pressure should not influence expiratory flows. When ventilatory support or hyperinflation is the primary goal of therapy, frequency should be decreased and pressure increased. The I/E time ratio should not influence ventilation. When percussive effect is the primary goal of therapy (ie, atelectasis, peripheral airway encumbrance, narrowed airways), percussion should be enhanced by increasing frequency, reducing $\mathrm{I} / \mathrm{E}$ time ratio, and increasing pressure. Finally, when PEEP effect is the primary goal of therapy, frequency, $\mathrm{I} / \mathrm{E}$ time ratio, and pressure should all be increased. In clinical practice, the therapeutic goals are often mixed. The subtlety of setting parameters is in obtaining the best compromise to optimize each of the best effects.

\section{Limitations of the Study}

As in any in vitro study, the present results cannot be transferred to humans without caution. Test lungs mimic human lungs imperfectly. The current study, however, offers a mapping of the effects on a test lung with normal and stable compliance and resistance. Future in vitro and in vivo studies are needed on lungs with altered characteristics of resistance and compliance typically representing the patients requiring this therapy.

Another limitation is that the test lung is totally passive. Indeed, IPV allows the subjects to breathe free in the circuit (an exception is the Pegaso, which offers resistance to expiration, as evidenced by elevated PEEP). It is known that spontaneous ventilation modulates the physical effects of IPV. ${ }^{14}$ During active expiration, percussions are more intense and expiratory flows are amplified. Future studies are recommended to investigate the physical effects of IPV in healthy subjects and in patients whose compliance and/or resistance are altered. 


\section{Conclusions}

In this study, 4 physical effects produced by portable IPV devices were measured, following the setting of frequency, I/E time ratio, and pressure. The results suggest that changing the parameters considerably modulates the mechanical effects produced by portable IPV devices in the lungs. Increasing frequency increased PEEP and percussion but decreased ventilation. Increasing I/E time ratio increased PEEP and E/I flow ratio, and decreased percussion. Finally, increasing pressure increased PEEP and ventilation. It also increased percussion when associated with minimal I/E time. The IMP2 and Impulsator produced the best mechanical effects, while the Pegaso produced the worst ones, as suggested by elevated PEEP, poor percussion, and minimal E/I flow ratio.

\section{REFERENCES}

1. Natale JE, Pfeifle J, Hommick DN. Comparison of intrapulmonary percussive ventilation and chest physiotherapy: a pilot study in patients with cystic fibrosis. Chest 1994;105(6):1789-1793.

2. Homnick DN, White F, de Castro C. Comparison of effects of an intrapulmonary percussive ventilator to standard aerosol and chest physiotherapy in treatment of cystic fibrosis. Pediatr Pulmonol 1995; 20(1):50-55.

3. Newhouse PA, White F. The intrapulmonary percussive ventilator and flutter device compared to chest physiotherapy in patients with cystic fibrosis. Clin Pediatr 1998;37(7):427-432.

4. Varekojis SM, Douce FH, Flucke RL, Filbrun DA, Tice JS, McCoy KS, Castile RG. Comparison of the therapeutic effectiveness of and preference for postural drainage and percussion, intrapulmonary percussive ventilation, and high-frequency chest wall compression in hospitalized cystic fibrosis patients. Respir Care 2003;48(1):24-28.

5. Van Ginderdeuren F, Verbanck S, Van Cauwelaert K, Vanlaethem S, Schuermans D, Vincken W, Malfroot A. Chest physiotherapy in cystic fibrosis: short-term effects of autogenic drainage preceded by wet inhalation of saline versus autogenic drainage preceded by intrapulmonary percussive ventilation with saline. Respiration 2008; 76(2):175-180.

6. Toussaint M, De Win H, Steens M, Soudon P. Effect of intrapulmonary percussive ventilation on mucus clearance in Duchenne muscular dystrophy patients: a preliminary report. Respir Care 2003; 48(10):940-947.

7. Clini EM, Antoni FD, Vitacca M, Crisafulli E, Paneroni M, ChezziSilva $\mathrm{S}$, et al. Intrapulmonary percussive ventilation in tracheostomized patients: a randomized controlled study. Intensive Care Med 2006;32(12):1994-2001.

8. Birnkrant DJ, Pope JF, Lewarski J, Stegmaier J, Besunder JB. Persistent pulmonary consolidation treated with intrapulmonary percussive ventilation: a preliminary report. Pediatr Pulmonol 1996;21(4):246-249.

9. Deakins K, Chatburn RL. A Comparison of intrapulmonary percussive ventilation and conventional chest physiotherapy for the treatment of atelectasis in the pediatric patient. Respir Care 2002;47(10): $1162-1167$

10. Yen Ha TK, Bui TD, Tran AT, Badin P, Toussaint M, Nguyen AT. Atelectatic children treated with intrapulmonary percussive ventilation via a face mask: clinical trial and literature overview. Pediatr Int 2007;49(4):502-507.

11. Reper P, Van Bos R, Van Loey K, Van Laeke P, Vanderkelen A. High frequency percussive ventilation in burn patients: hemodynamics and gas exchange. Burns 2003;29(6):603-608.
12. Hall JJ, Hunt JL, Arnoldo BD, Purdue GF. Use of high-frequency percussive ventilation in inhalation injuries. J Burn Care Res 2007; 28(3):396-400.

13. Chung KK, Wolf SE, Renz EM, Allan PF, Aden JK, Merrill GA, et al. High-frequency percussive ventilation and low tidal volume ventilation in burns: a randomized controlled trial. Crit Care Med 2010; 38(10):1970-1977.

14. Nava S, Barbarito N, Piaggi G, De Mattia E, Cirio S. Physiological response to intrapulmonary percussive ventilation in stable COPD patients. Respir Med 2006;100(9):1526-1533.

15. Vargas F, Bui HN, Boyer A, Salmi LR, Gbikpi-Benissan G, Guenard $\mathrm{H}$, et al. Intrapulmonary percussive ventilation in acute exacerbations of COPD patients with mild respiratory acidosis: a randomized controlled trial. Crit Care 2005;9(4):R382-R389.

16. Antonaglia V, Lucangelo U, Zin WA, Peratoner A, De Simoni L, Capitanio G, et al. Intrapulmonary percussive ventilation improves the outcome of patients with acute exacerbation of COPD using helmet. Crit Care Med 2006;34(12):2940-2945.

17. Vargas F, Boyer A, Bui HN, Guenard H, Gruson D, Hilbert G. Effect of intrapulmonary percussive ventilation on expiratory flow limitation in chronic obstructive pulmonary disease patients. J Crit Care 2009;24(2):212-219.

18. Chatburn RL. High-frequency assisted airway clearance. Respir Care 2007;52(9):1224-1235.

19. Kim CS, Iglesias AJ, Sackner MA. Mucus clearance by two-phase gas-liquid flow mechanism: asymmetric periodic flow model. J Appl Physiol 1987;62(3):959-971.

20. Benjamin RG, Chapman GA, Kim CS, Sackner MA. Removal of bronchial secretions by two-phase gas-liquid transport. Chest 1989; 95(3):658-663

21. King M, Zidulka A, Phillips DM, Wight D, Gross D, Chang HK. Tracheal mucus clearance in high-frequency oscillation: effect of peak flow rate bias. Eur Respir J 1990;3(1):6-13.

22. Freitag L, Long WM, Kim CS, Wanner A. Removal of excessive bronchial secretions by asymmetric high-frequency oscillations. J Appl Physiol 1989;67(2):614-619.

23. Volpe MS, Adams AB, Amato MB, Marini JJ. Ventilation patterns influence airway secretion movement. Respir Care 2008;53(10):12871294.

24. Reychler G, Keyeux A, Cremers C, Veriter C, Rodenstein D, Liistro G. Comparison of lung deposition in two types of nebulization: intrapulmonary percussive ventilation vs jet nebulization. Chest 2004; 125(2):502-508.

25. Falk M, Kelstrup M, Andersen JB, Falk M, Kelstrup M, Andersen JB, et al. Improving the ketchup bottle method with positive expiratory pressure (PEP) in cystic fibrosis. Eur J Respir Dis 1984;65(6):423-432.

26. Groth S, Stafanger G, Dirksen H, Andersen JB, Falk M, Kelstrup M. Positive expiratory pressure (PEP-mask) physiotherapy improves ventilation and reduces volume of trapped gas in cystic fibrosis. Bull Eur Physiopathol Respir 1985;21(4):339-343.

27. Perez A, Mulot R, Vardon G, Barois A, Gallego J. Thoracoabdominal pattern of breathing in neuromuscular disorders. Chest 1996; 110(2):454-461.

28. Ioos C, Leclair-Richard D, Mrad S, Barois A, Estournet-Mathiaud B. Respiratory capacity course in patients with infantile spinal muscular atrophy. Chest 2004;126(3):831-837.

29. Velmahos GC, Chan LS, Tatevossian R, Cornwell EE 3rd, Dougherty WR, Escudero J, Demetriades D. High-frequency percussive ventilation improves oxygenation in patients with ARDS. Chest 1999; 116(2):440-446.

30. Salim A, Miller K, Dangleben D, Cipolle M, Pasquale M. Highfrequency percussive ventilation : an alternative mode of ventilation for head-injured patients with adult respiratory distress syndrome. J Trauma 2004;57(3):542-546. 